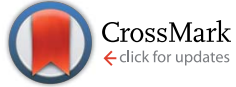

Cite this: RSC Adv., 2015, 5, 103494

Received 28th September 2015 Accepted 12th November 2015

DOI: $10.1039 / \mathrm{c} 5 \mathrm{ra} 20035 \mathrm{k}$

www.rsc.org/advances

\title{
Poly(ethylene oxide)-based block copolymers with very high molecular weights for biomimetic calcium phosphate mineralization $\uparrow$
}

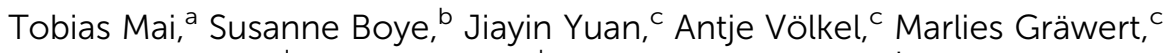 \\ Christina Günter, ${ }^{d}$ Albena Lederer ${ }^{\mathrm{b}}$ and Andreas Taubert ${ }^{\star a}$
}

\begin{abstract}
The present article is among the first reports on the effects of poly(ampholyte)s and poly(betaine)s on the biomimetic formation of calcium phosphate. We have synthesized a series of di- and triblock copolymers based on a non-ionic poly(ethylene oxide) block and several charged methacrylate monomers, 2(trimethylammonium)ethyl methacrylate chloride, 2-((3-cyanopropyl)-dimethylammonium)ethyl methacrylate chloride, 3-sulfopropyl methacrylate potassium salt, and [2-(methacryloyloxy)ethyl]dimethyl-(3-sulfopropyl) ammonium hydroxide. The resulting copolymers are either positively charged, ampholytic, or betaine block copolymers. All the polymers have very high molecular weights of over $10^{6} \mathrm{~g} \mathrm{~mol}^{-1}$. All polymers are water-soluble and show a strong effect on the precipitation and dissolution of calcium phosphate. The strongest effects are observed with triblock copolymers based on a large poly(ethylene oxide) middle block (nominal $M_{n}=100000 \mathrm{~g} \mathrm{~mol}^{-1}$ ). Surprisingly, the data show that there is a need for positive charges in the polymers to exert tight control over mineralization and dissolution, but that the exact position of the charge in the polymer is of minor importance for both calcium phosphate precipitation and dissolution.
\end{abstract}

\section{Introduction}

Human enamel predominantly consists of calcium-deficient carbonated hydroxyapatite (HAP). ${ }^{1}$ Enamel is a robust material that is excellently adapted to the stresses exerted on teeth over the course of an animal's lifetime. Nonetheless, daily stresses like mechanical impact on chewing, biological (e.g. caries), or chemical attacks (e.g. erosion) will damage the enamel irretrievably. Unfortunately however, biological repair mechanisms of teeth are, in contrast to bone, virtually non-existent. ${ }^{2}$ There are only different exogenous strategies to minimize these everyday stresses and the resulting damage such as (i) adjustment of nutrition to minimize acid intake, which will lead to reduced chemical attack of the enamel surface ${ }^{3-6}$ (ii) improving the resistance of the enamel by (chemical) surface modification, ${ }^{3,7-13}$ (iii) counteracting the attacks

\footnotetext{
${ }^{a}$ Institute of Chemistry, University of Potsdam, D-14476 Potsdam, Germany. E-mail: ataubert@uni-potsdam.de; Tel: +493319775773

${ }^{b}$ Leibniz Institut für Polymerforschung Dresden e.V., D-01069 Dresden, Germany

${ }^{c}$ Max Planck Institute of Colloids and Interfaces, D-14476 Potsdam, Germany

${ }^{d}$ Institute of Earth and Environmental Sciences, University of Potsdam, D-14476 Potsdam, Germany

$\dagger$ Electronic supplementary information (ESI) available: Analytical data of all polymers, IR-spectra and ${ }^{1} \mathrm{H}$ NMR spectra of polymers, $\mathrm{Cu}$ and $\mathrm{K}$ contents from ICP-OES, absolute data for calcium precipitation titration, $\kappa$ values for all polymers, EDXS data of precipitates, SEM images of all precipitates, XRD data of all precipitates, from HAP dissolution experiments. See DOI: 10.1039/c5ra20035k
}

of caries-inducing microorganisms, which will lead to a reduced biology-induced damage, ${ }^{\mathbf{1 4 - 2 0}}$ or (iv) repair the damaged enamel by remineralization ${ }^{14-16,21}$ or other technologies. ${ }^{22,23}$

There are several chemical strategies to stabilize the enamel. For example, the addition of fluoride ${ }^{7,13}$ to toothpastes or mouthwash facilitates the formation of resistant fluoridesubstituted hydroxyapatite or fluorapatite (FAP) in the outermost enamel section. Alternatively, fluoride-containing tin compounds $^{8-12}$ provide both a chemical stabilization via the fluoride and an antibacterial activity by way of the tin, which is located at the enamel surface and released over time. Other strategies to reduce biologically induced damage (i.e. caries) include the incorporation of antibacterial additives such as chlorhexidine $\mathbf{1 4 , 2 0}^{\mathbf{1} 20}$ or silver ${ }^{\mathbf{1 5 , 1 8}}$ into dental care products and their regular application in dental hygiene. A further possibility to reduce adverse effects is to interrupt biofilm formation ${ }^{24}$ before caries bacteria can settle on the enamel. ${ }^{25,26}$

A rather new development is the interest in chemical strategies for remineralization of damaged enamel and dentin. Generally, these strategies involve the use of a synthetic material for filling existing defects in enamel and dentin. For example, HAP or amorphous calcium phosphate (ACP) nanoparticles provide some stabilization. ${ }^{14-16,21}$ Moreover, some of these systems combine remineralizing and antibacterial activities, for example by combination of calcium phosphate with silver species ${ }^{15}$ or chlorhexidine. ${ }^{\mathbf{1 4 - 1 6}}$ One key issue here is that for a good functionality, the calcium phosphates must have 
a uniform size, shape, dimension, and chemical composition. This is often achieved via polymer additives that aid the calcium phosphate mineralization process. While there is a large body of work on polymer-controlled biomimetic calcium phosphate mineralization in general ${ }^{27-29}$ only a small fraction of the work focuses on dental applications.

One of these examples is the work of Kniep and coworkers, ${ }^{30-36}$ who described the formation of spherical FAP particles in gelatin hydrogels, mostly via double diffusion techniques. Initially, hexagonal rods form, which later on transform into fractal-like structures yielding FAP dumbbells and finally closed spheres. These materials fill dentin tubules and were later used as a functional component in the toothpaste Theramed S.O.S. sensitive.

In addition to inorganic compounds $s^{9,10,13,21,37-39}$ polymers like xanthan, ${ }^{\mathbf{4 0}}$ pectin, ${ }^{\mathbf{4 1}}$ casein $^{\mathbf{3}}$ and others ${ }^{\mathbf{2 4 , 4 0 - 4 2}}$ have also been used as additives in dental care products. Among others, these polymers are able to anchor on the surface of the teeth and act as barrier for protons or micro organisms.

Considering the chemical composition of the synthetic polymer additives used for calcium phosphate mineralization so far, ${ }^{27,28}$ the combination of poly(electrolyte)s with poly (ethylene oxide) (PEO) is one of the most popular choices. ${ }^{43-45}$ To a large extent, this is due the well-known biopassivation abilities of $\mathrm{PEO}^{46}$ and the strong interaction of poly(electrolyte)s with inorganic ions ${ }^{47-50}$ and surfaces. ${ }^{47,48,51-53}$ The combination of highly charged remineralizition-enhancing ${ }^{\mathbf{4 8 , 4 9 , 5 4 - 6 2}}$ or dissolution-limiting ${ }^{\mathbf{6 3 , 6 4}}$ polymer segments with the biopassivation of PEO is thus a viable strategy towards multifunctional polymers providing both anti-biofilm and remineralization-enhancing behavior in one single system.

In spite of this, there are only very few studies combining the two roles in one polymer. We have previously shown that negatively charged poly(sulfonate)-based block copolymers are efficient growth control agents for calcium phosphate and at the same time also reduce bacterial adhesion on the enamel surface. ${ }^{65}$

Clearly, an ideal additive should (i) adhere to the enamel surface without further damaging it, (ii) function as protective shield against incoming acids and bacteria, (iii) show bactericidal or bacteria-repellent properties, and (iv) initiate the remineralization at the damaged enamel surface sites.

Interestingly, positively charged, ${ }^{59,66-69}$ ampholytic, $^{70}$ or betainic $^{\mathbf{6 0 , 6 1 , 7 1}}$ additives for calcium phosphate mineralization are much less common, despite the fact that such polymers show bactericidal $^{72-74}$ and antifouling ${ }^{75-77}$ properties that should also be interesting for dental applications. Additionally, these polymers are able to interact with solids. ${ }^{78,79}$ The lack of studies on poly(cationic) additives is all the more surprising because the positive charge could also be interesting for phosphate enrichment and for improving the contact to the enamel surface, which is slightly negatively charged ${ }^{80}$ at $c a .-0.02 \mathrm{C} \mathrm{m}^{-2}$. Accordingly, positively charged polymers could interact with the enamel surface and therefore offer a means of modifying the enamel surface for protection against biofilm formation and remineralization control at the same time. The current study therefore focuses on the role of PEO-based block copolymers, where the charged block is cationic, ampholytic, or betainic in nature, for biomimetic calcium phosphate mineralization.

\section{Experimental part}

\section{Materials}

Copper(I) chloride (technical grade, Carl Roth and Merck); ethylene diamine tetraacetic acid disodium salt (EDTA/ $\mathrm{Na}_{2}$, Roth), [2-(methacryloyloxy)ethyl]dimethyl-(3-sulfopropyl)ammonium hydroxide (MEDSAH, 97\%, Merck), 2-(dimethylamino)ethyl methacrylate (DMAEMA, $\geq 99 \%$, containing monomethyl ether hydroquinone as inhibitor, Merck), 4-bromobutyronitrile (97\%, abcr), poly(ethylene oxide) (PEO100k, nominal $M_{\mathrm{n}}=100000 \mathrm{~g}$ $\mathrm{mol}^{-1}$, abcr), ammonium sulfate ( $\geq 99.0 \%$, Sigma-Aldrich), $\alpha$ bromoisobutyryl bromide (98\%, Sigma-Aldrich), poly(ethylene oxide) (PEO4600, nominal $M_{\mathrm{n}}=4600 \mathrm{~g} \mathrm{~mol}^{-1}$, Sigma-Aldrich), poly(ethylene oxide monomethylether) (MPEO5000, nominal $M_{\mathrm{n}}=5000 \mathrm{~g} \mathrm{~mol}^{-1}$, Sigma-Aldrich), potassium peroxodisulfate (KPDS, $\geq 99 \%$, Sigma-Aldrich), 3-sulfopropylmethacrylate potassium salt, (SPM, 98\%, Sigma-Aldrich), 2-(trimethylammonium) ethyl methacrylate chloride (TMAEMA, $80 \mathrm{wt} \%$ in water, SigmaAldrich), and synthetic hydroxyapatite powder (Sigma-Aldrich, 98\%) were used as received. $N, N, N^{\prime}, N^{\prime}$-tetramethyl ethylenediamine (TMEDA, $\approx 99 \%$, Sigma-Aldrich) and triethylamine ( $\geq 99 \%$, Sigma-Aldrich) were dried with phosphorous pentoxide. Solvents and polytetrafluoroethylene (PTFE) syringe filters were purchased from VWR international and used as received.

\section{Monomer synthesis}

The non-commercial monomer 2-((3-cyanopropyl)-dimethylammonium)ethyl methacrylate chloride (CPDMAEMA/Cl) was made by modification of DMAEMA. In a two neck flask $70 \mathrm{mmol}$ (10.95 mL, 1 equivalent) of DMAEMA were dissolved in $20 \mathrm{~mL}$ of $\mathrm{CHCl}_{3}$. Subsequently, $70 \mathrm{mmol}(6.45 \mathrm{~mL}, 1.0$ equivalent $)$ of 4-bromobutyronitrile dissolved in $30 \mathrm{~mL}$ of $\mathrm{CHCl}_{3}$ were added. The mixture was stirred at $50{ }^{\circ} \mathrm{C}$ for 1 day. After the addition of $50 \mathrm{~mL}$ of hexane, the $\mathrm{CHCl}_{3} /$ hexane phase was removed. The colorless highly viscous residue was washed three times with 100 $\mathrm{mL}$ of hexane and two times with $50 \mathrm{~mL}$ of dioxane. The white viscous product was suspended in $50 \mathrm{~mL}$ of dioxane and freezedried to yield a white solid with $55-65 \%$ yield. The resulting monomer CPDMAEMA/Br is fairly stable but should be stored under argon because of its highly hygroscopic character.

The chloride form CPDMAEMA/Cl was made by ion exchange chromatography using an aqueous, slightly yellow, solution of CPDMAEMA/Br on a DOWEX $1 \times 4-50$ ion exchange resin. Completion of the exchange was verified with an $0.2 \mathrm{M}$ silver nitrate solution. After removing the main part of the water under reduced pressure at $30{ }^{\circ} \mathrm{C}$, the remaining water was removed by freeze-drying yielding a white solid. The product could only be stored under argon in the refrigerator for a few weeks as it tends to self-polymerize.

FTIR (ATR, $298 \mathrm{~K}$ ): $2924 \mathrm{~cm}^{-1}$, C-H asymmetric stretching vibration; $2247 \mathrm{~cm}^{-1}$, CN stretching vibration; $1716 \mathrm{~cm}^{-1}, \mathrm{C}=\mathrm{O}$ stretching vibration; $1634 \mathrm{~cm}^{-1}, \mathrm{C}=\mathrm{O}$ stretching; $1453 \mathrm{~cm}^{-1}$, $\mathrm{C}-\mathrm{H}$ scissor vibration; $1294 \mathrm{~cm}^{-1}, \mathrm{CH}_{2}$ in-plane deformation 
vibration; $1156 \mathrm{~cm}^{-1}, \mathrm{C}-\mathrm{N}$ stretching vibrations. ${ }^{1} \mathrm{H}$ NMR $(300$ $\left.\mathrm{MHz}, \mathrm{D}_{2} \mathrm{O}, 298 \mathrm{~K}\right) d \mathrm{ppm} 1.94(\mathrm{t}, J=1.32 \mathrm{~Hz}, 3 \mathrm{H}) 2.19-2.31(\mathrm{~m}$, $2 \mathrm{H}) 2.66(\mathrm{t}, J=7.06 \mathrm{~Hz}, 2 \mathrm{H}) 3.23(\mathrm{~s}, 6 \mathrm{H}) 3.56$ (dquin, $J=7.50$, $4.00,4.00,4.00,4.00 \mathrm{~Hz}, 2 \mathrm{H}) 3.81-3.87(\mathrm{~m}, 2 \mathrm{H}) 4.64(\mathrm{tt}, J=4.70$, $2.30 \mathrm{~Hz}, 2 \mathrm{H}$ ) 5.78 (quin, $J=1.50 \mathrm{~Hz}, 1 \mathrm{H}$ ) 6.16 (quin, $J=0.90 \mathrm{~Hz}$, 1H). EA experiment (calculated): C 43.3\% (47.1\%), H 7.1\% (7.2\%), N 8.9\% (9.2\%). HRMS (ESI-Q-TOF) $m / z:\left[\mathrm{M}-\mathrm{Br}^{-}\right]^{+}$calcd for $\mathrm{C}_{12} \mathrm{H}_{21} \mathrm{~N}_{2} \mathrm{O}_{2}$ 225.1603; found 225.1598. [M $\left.-\mathrm{Br}^{-}+1 \mathrm{H}\right]^{+}$ calcd for $\mathrm{C}_{12} \mathrm{H}_{21} \mathrm{~N}_{2} \mathrm{O}_{2}$ 226.1676; found 226.1624.

\section{Macroinitiators}

Macroinitiator synthesis was done as described previously ${ }^{65}$ but using $\alpha$-bromoisobutyryl bromide instead of bromoacetyl bromide to increase the rate of initiation with the TMAEMA and CPDMAEMA monomers. Fig. 1 shows the macroinitiators used in this study.

\section{Polymerization}

Prior to polymerization, $\mathrm{CuCl}$ was cleaned and activated with glacial acetic acid followed by washing with ethanol and methyl tert-butyl ether (MTBE) ${ }^{50}$ Alternatively, CuCl was dissolved in aqueous $\mathrm{HCl}(25 \%)$ and reprecipitated by addition of water followed by washing with ethanol and MTBE. ${ }^{\mathbf{8 2 , 8 3}}$ After both procedures the copper(I) chloride was dried at reduced pressure and stored under Ar.

\section{General polymerization procedure - 1. homopolymers}

In a two neck flask the monomers were dissolved in water. The solution was flushed with argon and degassed five times. Then the initiator was added and the flask was sealed with a septum. The reaction mixture was stirred at $60{ }^{\circ} \mathrm{C}$ for $90 \mathrm{~min}$. Then the flask was opened and air was bubbled through the reaction mixture to terminate the reaction. In the cases, where TMAEMA was used the liquid volume was reduced to $c a$. $50 \%$ by rotary evaporation. Purification was done by repeated precipitation. Sample nomenclature and analytical data of all polymers are given in Table S1.†

\section{General polymerization procedure -2 . block copolymers}

In a two neck flask, the macroinitiator MI1 and the respective monomer were dissolved in water. The mixture was degassed and flushed 5 times with argon. Then $\mathrm{CuCl}$ and TMEDA were added, the flask was sealed with a septum, and the reaction mixture was stirred for 40-150 minutes at room temperature. To stop the reaction air was bubbled through the solution for 1 min. The product was precipitated from $300 \mathrm{~mL}$ of isopropyl alcohol and washed with MTBE. ${ }^{\mathbf{8 2 8 3}}$ Purification was done by repeated precipitation. The final product was obtained by freeze-drying. Sample nomenclature and analytical data are given in Table $\mathrm{S} 1 \dagger$ and Table 1 . Chemical structures of all polymers are given in Fig. 2.

\section{Mineralization}

Mineralization was done as described previously. ${ }^{65}$ In a typical experiment, $150 \mathrm{mg}$ of a polymer were dissolved in $30 \mathrm{~mL}$ of doubly concentrated simulated body fluid (2SBF). 2SBF is a wellestablished system for artificial saliva first introduced by Kokubo et al. ${ }^{84}$ Then $15 \mathrm{~mL}$ of aqueous $0.1 \mathrm{M} \mathrm{CaCl}_{2}$ were added in three $5 \mathrm{~mL}$ steps interrupted by vortexing for $30 \mathrm{~s}$. This mixture was stirred for 5 days at $500 \mathrm{rpm}$ at room temperature. The product was purified by centrifugation and washing five times with pure water $(\rho=18.2 \mathrm{M} \Omega \mathrm{cm})$ and ethanol.

\section{Polymer-induced calcium phosphate dissolution}

Calcium phosphate dissolution was measured as described earlier. ${ }^{65}$ In $10 \mathrm{~mL}$ of millipore water $(\rho=18.2 \mathrm{M} \Omega \mathrm{cm}) 100 \mathrm{mg}$ of synthetic HAP powder were suspended and 2 to $50 \mathrm{mg}$ of a polymer were dissolved. The mixtures were shaken for 10 days at room temperature. After centrifugation and filtration through a $0.2 \mu \mathrm{m}$ PTFE syringe filter the concentration of $\mathrm{Ca}^{2+}$ in the aqueous phase was determined via ICP-OES.

\section{Asymmetric flow field-flow fraction}

AF4 measurements were performed on a Eclipse 3 system (Wyatt) with a regenerated cellulose membrane (10 kDa cutoff) and a channel height of $350 \mu \mathrm{m}$ using water with $0.2 \%$ sodium azide and $50 \mathrm{mmol} \mathrm{L}^{-1} \mathrm{NaNO}_{3}$ as eluent. For detection, an Agilent Technologies UV-detector, a DAWN EOS multi-angle scattering detector (Wyatt Technologies), and an Optilab TrEX RI-detector (Wyatt) at $690 \mathrm{~nm}$ were used. A flow rate of 1 $\mathrm{mL} \min ^{-1}$ at $25{ }^{\circ} \mathrm{C}$ was used with an exponential cross flow gradient from 3 to $0 \mathrm{~mL} \min ^{-1}$ for $15 \mathrm{~min}$ using a curve multiplier of 2.5. The sample size was $100 \mu \mathrm{L}$ for $\mathrm{C} 1, \mathrm{C} 2{ }^{\mathrm{CN}}, \mathrm{C} 3{ }^{\mathrm{CN}}$ and $50 \mu \mathrm{L}$ for $\mathrm{C} 2, \mathrm{C} 3, \mathrm{~B} 1, \mathrm{~B} 3, \mathrm{~B} 4$. Polymer concentration was $1.000 \mathrm{mg} \mathrm{mL}^{-1}$.

\section{Elemental analysis}

EA was done on a Vario EL III (elementar).

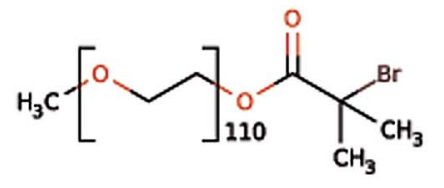

MI1

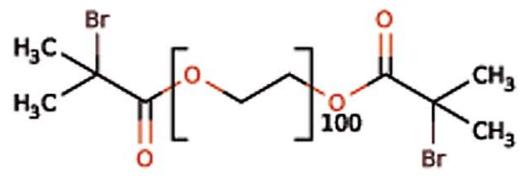

MI4<smiles>CC(C)(Br)C(=O)OCCCOC(=O)C(C)(C)Br</smiles>

MI5

Fig. 1 Macroinitiators used in the present study. ${ }^{81} \mathrm{MI}$ is macroinitiator, MI2 and MI3 (not shown here) have been used in the previous study ${ }^{65}$ but have been replaced by MI4 and MI5, respectively, because MI4 and MI5 are more reactive than MI2 and MI3. Based on PEO these starters will lead to a biopassive block ${ }^{46}$ in the later block copolymers. 
Table 1 Summary of analytical data for the polymers used in this study. Empty fields indicate that these data have not been accessible, for details see the experimental part and discussion below

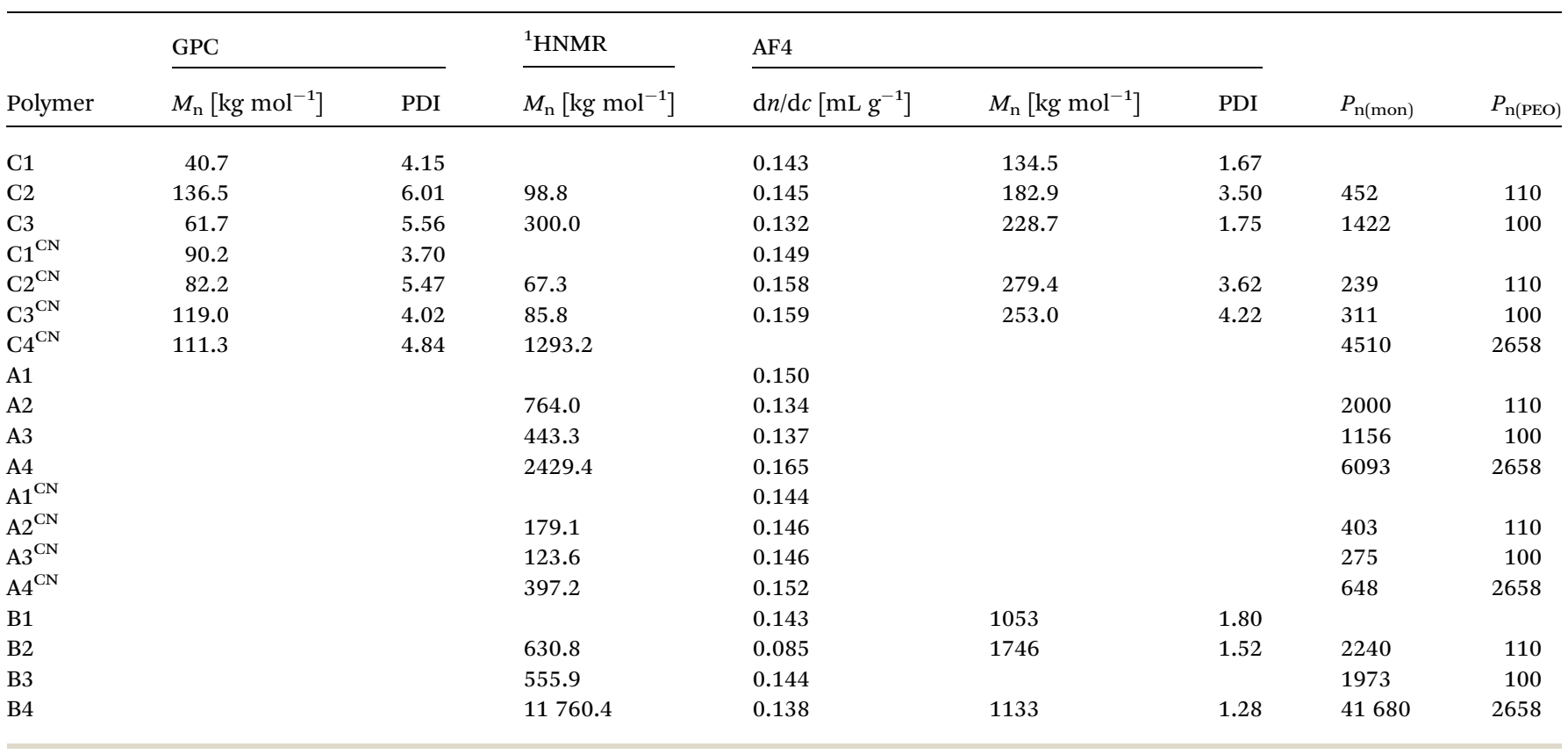

\section{Gel permeation chromatography}

Cationic polymers: GPC with simultaneous UV, RI, and MALLS (multi-angle laser light scattering, Wyatt Dawn Eos) detection was performed at room temperature in acetate buffer with $20 \%$ of methanol, a flow rate of $1.0 \mathrm{~mL} \mathrm{~min}^{-1}$, and using a PSS Novema MAX analytical linear S 10 column with porosities of $10 \mu \mathrm{m}$. Solutions containing $\sim 0.15 \mathrm{wt} \%$ polymer were filtered through $0.45 \mu \mathrm{m}$ filters; the injected volume was $100 \mu \mathrm{L}$. Data<smiles>CCC(C)(C)C(C(=O)OCCCl)C(C)(C)CC[N+](C)(C)C</smiles><smiles>CCC(C)(C)C(C(=O)OCCCl)C(C)(C)CC[N+](C)(C)CCCC#N</smiles>

P(TMAEMA)

C1<smiles>CC(CCC(C)(C)C)OC(=O)C(C)(C)Br</smiles>

C2

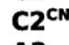

A2

A2

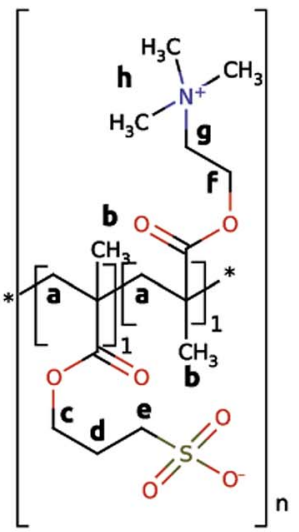

P(TMAEMACOSPM)

A1<smiles>[R]C(C)(C)C(=O)OCC[13C]1(CCOC(=O)C(C)(C)C)CC1</smiles>

C3

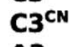

A3

$\mathrm{A3}^{\mathrm{CN}}$

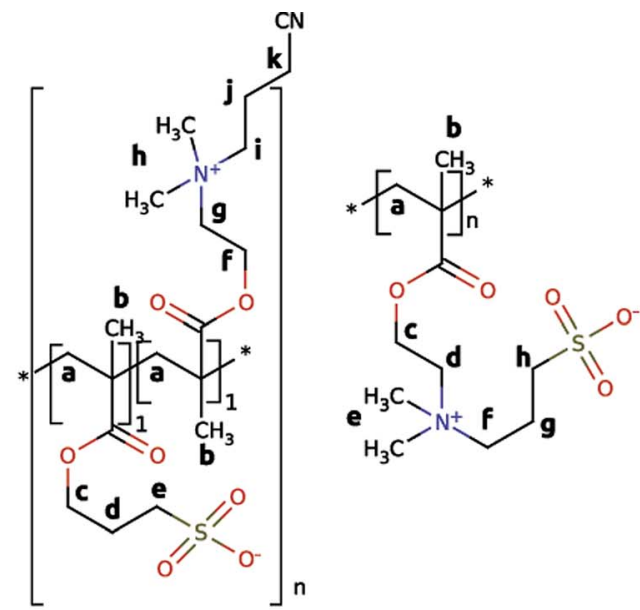

P(CPDMAEMACOSPM)<smiles>[R]C(C)([Ge]Cl)C(=O)C(C)(COCCCC)C(=O)C(C)(C)C</smiles>

Fig. 2 Chemical structures of the polymers synthesized in the present study. ${ }^{81}$ The lower case labels refer to ${ }^{1} \mathrm{H}$ NMR assignments shown in Fig. 3 below. 
were recorded and evaluated with the PSS-WinGPC Unichrom software package.

\section{Inductively coupled plasma-optical emission spectroscopy}

ICP-OES experiments were performed on a VARIAN Vista MPX with axial plasma by dilution with water.

\section{Infrared spectroscopy}

ATR-IR-spectra were recorded on a Thermo Nicolet 6700 from 500 to $4000 \mathrm{~cm}^{-1}$ at $1 \mathrm{~cm}^{-1}$ resolution and at least 32 scans per measurement. Data were evaluated with the Omnic 6.2 software.

\section{NMR spectroscopy}

NMR spectra were recorded on a Bruker Avance 300 at room temperature.

\section{Mass spectrometry}

Mass spectra were measured on an ESI-Q-TOF micro (Quadrupole-Time of Flight).

\section{Scanning electron microscopy \& energy-dispersive X-ray spectroscopy}

SEM and EDXS experiments were done on a JEOL JSM-6510 with an INCA-x-act detector. Acceleration voltage was $15 \mathrm{kV}$ for EDXS and 8 to $15 \mathrm{kV}$ for SEM. All samples were carbon-coated for 5 seconds using an EMITECH SC7620 sputter coater. For preparation the samples were dispersed in $5 \mathrm{~mL}$ ethanol, a few drops of the dispersion were deposited on the SEM sample holders and the ethanol was allowed to dry prior to inserting the samples into the microscope.

\section{Turbidimetry}

The turbidity evolution during calcium phosphate precipitation reactions was quantified with a Shimadzu UV mini 1240 at 746 $\mathrm{nm}$ following a previously published protocol. ${ }^{65}$ The critical $\mathrm{Ca}^{2+}$ for precipitation concentration $[\mathrm{Ca}]^{\mathrm{P}}$ was obtained from $x_{0}$ of the equation $y=A_{1}+\left(A_{2}-A_{1}\right) /\left(1+\mathrm{e}^{\left(x-x_{0}\right) / \mathrm{d} x}\right)$, with $A_{1}$ as the initial value, $A_{2}$ as the final value, $x_{0}$ as the function center and $\mathrm{d} x$ as the steepness of the fit. All measurements were reproduced in triplicate.

\section{X-ray diffraction}

XRD experiments were done on a Siemens D5005 X-ray diffractometer with $\mathrm{Cu}$ anode and vertical circle goniometer with an optional sample holder for small amounts of sample. For preparation all samples were dispersed in $5 \mathrm{~mL}$ ethanol.

\section{Results}

\section{Polymer synthesis and composition}

Polymers were characterized with ${ }^{1} \mathrm{H}$ NMR spectroscopy, gel permeation chromatography (GPC), and asymmetric field-flowfield fractionation (AF4), Table 1, proving that in all cases polymers with very high molecular weights are obtained. Consistent with literature, AF4 detects higher molecular weights than ${ }^{1} \mathrm{H}$ NMR spectroscopy. ${ }^{85,86}{ }^{1} \mathrm{H}$ NMR spectroscopy further confirms that the copolymers made from either TMAEMA or CPDMAEMA/Cl (the cationic monomers) and the anionic monomer SPM have a 1:1 monomer ratio (Fig. 3 and S7-S11 $\dagger$ ). Further experiments using inductively coupled plasma-optical emission spectroscopy (ICP-OES) confirm that all polymers contain low fractions of $\mathrm{Cu}$ from the initiator and a slightly higher fraction of $\mathrm{K}$ from the SPM monomer in case of A-type (ampholyte) or from purification in the case of B-type (betaine) polymers (Table S12 $\dagger$ ). In spite of the fact that for all polymers analytical data can be provided, there are significant differences between the ampholytic A, betainic B, and cationic C-type polymers. These will now be discussed in more detail, starting with the cationic $\mathrm{C}$ polymers.

Under the experimental conditions chosen here, the cationic monomers TMAEMA and CPDMAEMA/Cl polymerize very slowly. Moreover, the high-molecular-weight macroinitiator MI5 shows poor initiation, which overall leads to very low conversions and yields below 9\% for the combination of MI5 and TMAEMA or CPDMAEMA/Cl. The polymerization with the macroinitiators
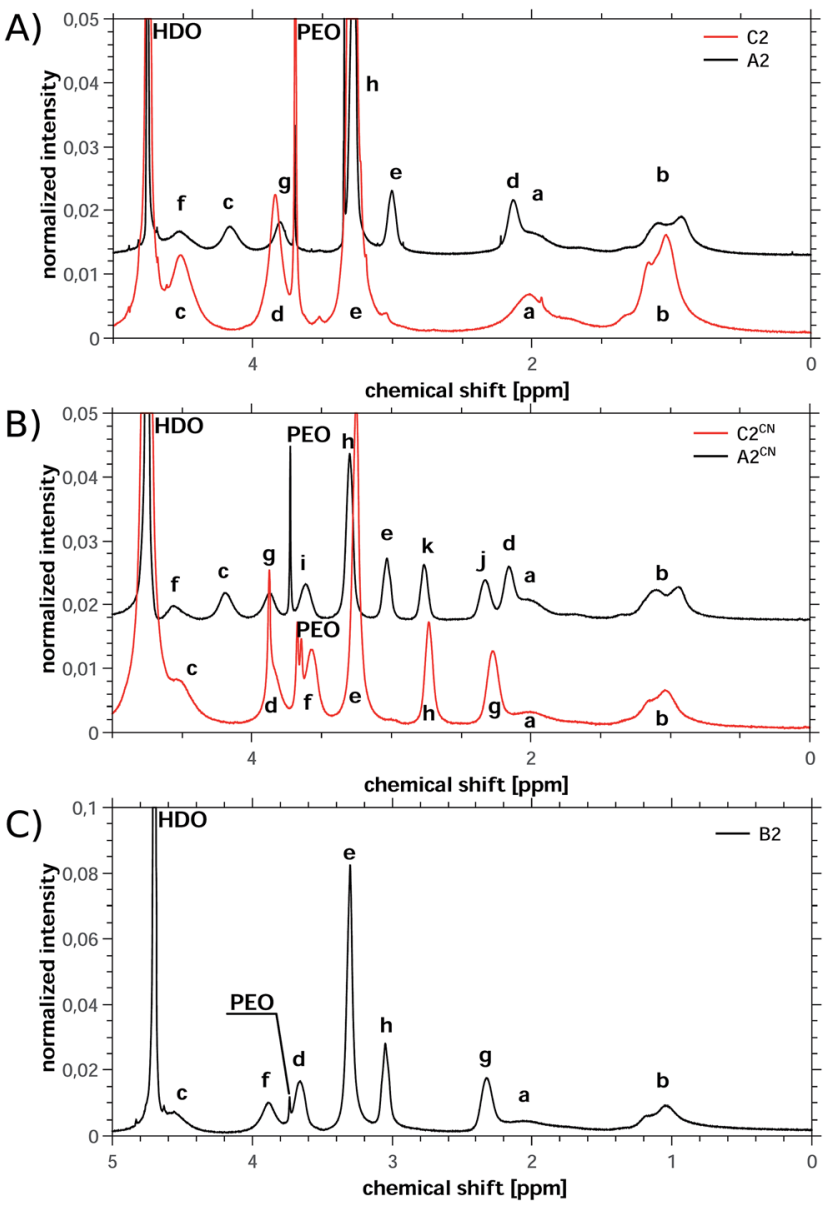

Fig. 3 Representative ${ }^{1} \mathrm{H}$ NMR spectra of (A) $\mathrm{C} 2$ and $\mathrm{A} 2$, (B) $\mathrm{C} 2{ }^{\mathrm{CN}}$ and $\mathrm{A} 2^{\mathrm{CN}}$ and $(\mathrm{C}) \mathrm{B} 2 . \mathrm{A} 2, \mathrm{~A} 2^{\mathrm{CN}}$ and $\mathrm{B} 2$ were measured in the presence of $\mathrm{KCl}$ to improve solubility. Labels for peak assignments are given in Fig. 2. 
MI1 and MI4 is much more efficient (likely due to the lower molecular weight of MI1 and MI4) and the respective polymers can be isolated in reasonable yields ( $21 \%$ for C 3 and over $55 \%$ for all other C-type polymers).

${ }^{1} \mathrm{H}$ NMR proves the successful polymer synthesis for all cationic polymers enabling the determination of the molecular weight of all individual blocks from NMR data. The infrared spectra on the other hand confirm the presence of the cationic blocks, but do not show any signal that can be assigned to the PEO-based macroinitiators. This indicates, consistent with NMR spectroscopy, that the PEO fraction in the copolymers is rather low. However for the cationic polymers based on CPDMAEMA/Cl the infrared spectra also prove the stability of the cyanide group by the presence of the signal at $2248 \mathrm{~cm}^{-1}$.

All polyampholytes were synthesized using a molar monomer ratio (cation : anion) of $1: 1$. Indeed, ${ }^{1} \mathrm{H}$ NMR spectroscopy confirms a $1: 1$ monomer ratio in the final polymers after purification. This is consistent with the work of Salamone ${ }^{87}$ and likely has its cause in a preorganization of the monomers in solution where a negatively charged SPM monomer is always nearby a positively charged ammonium monomer, TMAEMA or CPDMAEMA/Cl in our case.

Additionally the presence of both monomers is also confirmed by IR spectroscopy, which detects bands at 1037, 1041 , and $1110 \mathrm{~cm}^{-1}$ indicative of the symmetric and asymmetric $\mathrm{SO}_{3}$ vibrations (SPM monomer) and bands at 1153 and $3046 \mathrm{~cm}^{-1}$ indicative of the $\mathrm{C}-\mathrm{N}$ stretching vibrations in the TMAEMA and CPDMAEMA/Cl monomers, respectively. In contrast, no signal from the PEO blocks could be observed. This again indicates a relatively low mass fraction of the PEO blocks in the final polymers, consistent with NMR data.

From all polymers studied here, the betaine-based polymers could best be purified resulting in very low fractions of remaining copper and potassium (Table S12†). ${ }^{1} \mathrm{H}$ NMR again shows the successful formation of the copolymers. The presence of signals from the PEO block and the betaine block enables the determination of the molecular weight from NMR spectroscopy (Table 1). B4 is the polymer with the highest molecular weight of the present study (Table 1) which is consistent with our previous study ${ }^{65}$ in the sense that the large PEO block again leads to the largest overall molecular weight. Consistent with the IR spectroscopy data on the polymers discussed above, also here, IR spectra only show signals characteristic of the betaine block, but not the PEO block (Fig. S2-S6†). Overall, these data show that the polymers are clean and have a well-defined composition, thus making them suitable additives for mineralization.

\section{Calcium phosphate mineralization}

We have previously shown that block copolymers made from essentially the same macroinitiators and SPM significantly delay the precipitation of calcium phosphate..$^{65}$ To evaluate the efficiency of the current copolymers in calcium phosphate mineralization or inhibition we have again used the precipitation titration method introduced in our previous study. ${ }^{65}$ In short, calcium chloride was added to a calcium and phosphate-containing stock solution containing the polymer; by further addition of calcium chloride it is possible to determine, how effectively a polymer delays or accelerates precipitation of the mineral in relation to control reactions in the absence of polymer.

Fig. 4 shows the calcium concentrations where precipitation was observed $v s$. the polymer composition. Somewhat surprisingly, the polymer chemistry appears to be of minor importance, as in all cases (cationic vs. ampholytic vs. betainic vs. anionic ${ }^{65}$ ) the calcium concentration at which precipitation is observed is in the same range of around $0.7 \mathrm{mg} \mathrm{mL}^{-1}$. Only $\mathrm{C}_{2}^{\mathrm{CN}}\left(c a .0 .9 \mathrm{mg} \mathrm{mL}^{-1}\right), \mathrm{C}^{\mathrm{CN}}\left(c a .0 .9 \mathrm{mg} \mathrm{mL}^{-1}\right)$, and PSPM- $b$ PEO100k-b-PSPM ( $c a .1 .1 \mathrm{mg} \mathrm{mL}^{-1}$ ) stabilize solutions with much higher supersaturation. In absence of polymer-additives precipitation occurs at $0.542 \mathrm{mg} \mathrm{mL}^{-1}$.

Although the precipitation concentration $[\mathrm{Ca}]^{\mathrm{P}}$ is roughly identical for all chemical groups present in the polymers, the particle morphologies of the precipitates obtained here differ significantly from products precipitated with the anionic block copolymers studied previously. While in the earlier case ${ }^{65}$ using 3-sulfopropyl methacrylate-based copolymer additives, relatively uniform spherical particles with diameters between 1 and a few $\mu \mathrm{m}$ were obtained, the cationic, ampholytic, and betainic additives studied here yield products that appear to be composed of much smaller nanoparticles. The particles are densely aggregated, which makes the determination of individual particle sizes and shapes more difficult than in the previous case. Nevertheless, the samples are homogeneous in themselves and do not contain two or more different particle types, Fig. 5.

The samples were further studied with energy dispersive X-ray spectroscopy (EDXS). In all cases, Ca, P, O, S, C, Na, and Cl were found. The presence of $\mathrm{Na}$ and $\mathrm{Cl}$ is due to the fact that the SBF used for calcium phosphate precipitation contains $\mathrm{NaCl}$. Some of the Cl may also have been introduced by the cationic polymers which have a chloride counterion. The presence of $\mathrm{O}$ is due to the polymer, the phosphate ions, and possibly the tape used to hold the samples on the SEM sample holder. The S and C is due to the

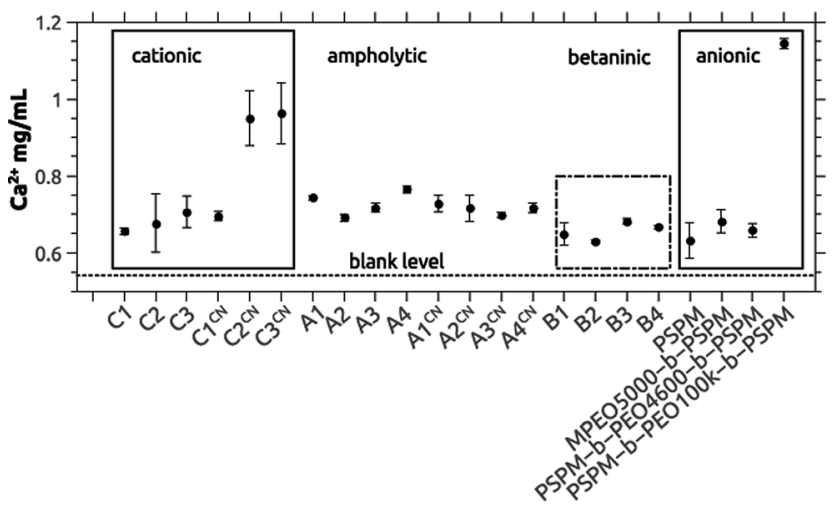

Fig. 4 Precipitation concentrations $[\mathrm{Ca}]^{\mathrm{P}}$ determined by turbidity measurements using the titration method described in ref. 65. Data on the anionic block copolymers are from ref. 65 . The dashed line at the bottom of the graph represents $[\mathrm{Ca}]^{\mathrm{P}}$ determined for samples without polymer additives (control sample). Absolute values are given in Table S13. $\dagger^{88}$ A single factor ANOVA analysis reveals that the average is the same. 

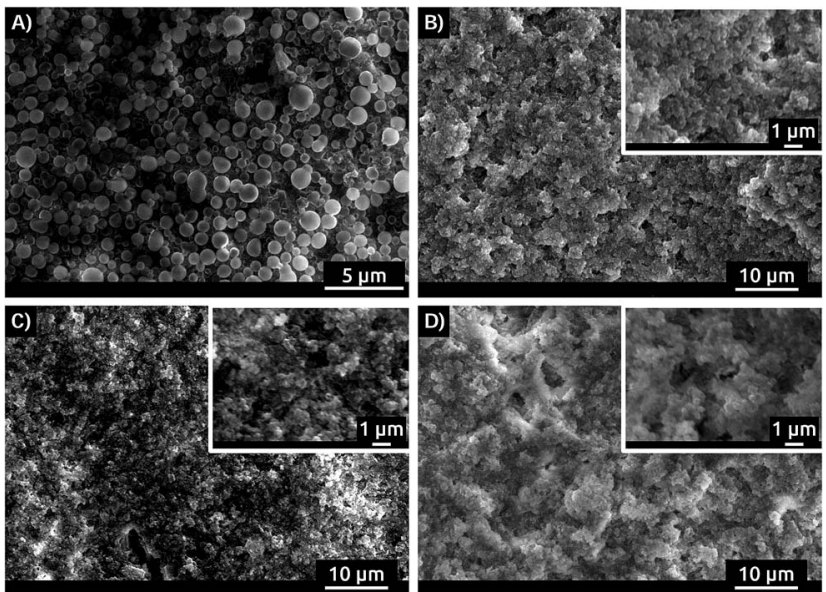

Fig. 5 SEM images of precipitate obtained in presence of (A) MPEO5000-b-PSPM, (B) B3, (C) C3 ${ }^{\mathrm{CN}}$ and (D) A1 ${ }^{\mathrm{CN}}$. SEM images of all polymers present in this study are shown in S17. $\dagger$

polymer and the tape. $\mathrm{Ca}$ and $\mathrm{P}$ are due to the $\mathrm{Ca}$ and phosphate ions in the calcium phosphate precipitate.

The $\mathrm{Ca} / \mathrm{P}$ ratios obtained from the EDX experiments (Fig. 6A, Table S16†) range from 1.33 to 1.52 . The only exception are the samples precipitated with $\mathrm{C}^{\mathrm{CN}}$ where $\mathrm{Ca} / \mathrm{P}=1.15$ is observed. This is even below the $\mathrm{Ca} / \mathrm{P}$ ratios for amorphous calcium phosphate ( $\mathrm{ACP}, \mathrm{Ca} / \mathrm{P}=1.5$ ) or octacalcium phosphate (OCP, $\mathrm{Ca} / \mathrm{P}=1.33)$. The $\mathrm{Ca} / \mathrm{P}$ ratio of $c a .1 .15$ in the samples grown with $\mathrm{C}^{\mathrm{CN}}$ of 1.15 could indicate a mixture of phases, possibly containing brushite, a highly calcium-deficient form of hydroxyapatite, or an OCP-like phase. ${ }^{89,90}$

Indeed, X-ray diffraction (Fig. $6 \mathrm{~B}$ and $\mathrm{S} 18 \dagger$ ) shows that all samples are composed of HAP (JCPDS 03-0747, $\mathrm{Ca}_{10}\left(\mathrm{PO}_{4}\right)_{6}{ }^{-}$ $\left.(\mathrm{OH})_{2}\right)$. Although the patterns are noisy and exhibit low count rates (approximately 100-300) the main reflections could be assigned to HAP. This also applies to the samples obtained with $\mathrm{C} 1{ }^{\mathrm{CN}}$, the sample exhibiting the low $\mathrm{Ca} / \mathrm{P}$ ratio of only 1.15 .

\section{Calcium phosphate dissolution}

We have previously shown that the polymers based on the SPM monomer have a beneficial effect on bacterial colonization of human enamel. ${ }^{65}$ An application in dental care can thus also be envisioned for the polymers studied here. An important factor to consider is the effect the polymers have on enamel stability, that is, whether or not the polymers dissolve the enamel of a tooth. Only polymers that do not significantly damage the enamel are candidates for application in dental care.

To evaluate whether the current polymers are able to dissolve HAP (and hence damage enamel) we have studied the dissolution of synthetic HAP vs. polymer chemistry and polymer concentration. Dispersions of synthetic HAP in water with and without polymer present were used to evaluate the HAP dissolution efficiency. The amounts of $\mathrm{Ca}^{2+}$ released from the HAP powder $v s$. polymer chemistry and concentration were quantified using ICP-OES.

Fig. 7, 8, S14 and S15† summarize the results of the dissolution studies. Fig. 8 shows that the betaine-based copolymers are most attractive in that here, an increasing polymer concentration does not lead to an increased calcium phosphate dissolution. In contrast, the poly(ampholyte)s show a slight increase of the calcium concentration with polymer concentration and the poly(cation)s show an even stronger increase in calcium phosphate dissolution $v s$. polymer concentration.

To better compare the effects, we have further used the dissolution parameter $\kappa$ (eqn (1)) where $n$ (monomer) is calculated from the respective molecular mass $M_{\mathrm{n}}$ and degree of polymerization $P$ of the polymers used in this study. $\kappa$ enables the comparison of the dissolution efficiency $v s$. numbers of functional monomers instead of polymer concentration and hence allows for the determination of relative dissolution effectiveness Fig. 7, 8, S14 and S15 $\dagger$ summarize the results of the dissolution studies. Fig. 7 shows that the betaine-based copolymers are most attractive in that here, an increasing polymer concentration does not lead to an increased calcium phosphate dissolution. In contrast, the poly(ampholyte)s show a slight increase of the calcium concentration with polymer concentration and the poly(cation)s show an even stronger increase in calcium phosphate dissolution $v s$. polymer concentration.

To better compare the effects, we have further used the dissolution parameter $\kappa$ (eqn (1)) where $n$ (monomer) is calculated from the respective molecular mass $M_{\mathrm{n}}$ and degree of polymerization $P$ of the polymers used in this study. $\kappa$ enables the comparison of the
A)

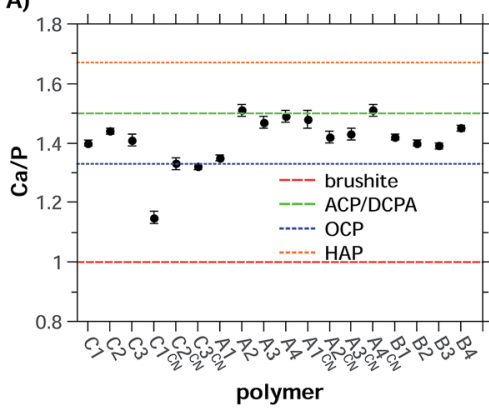

B)

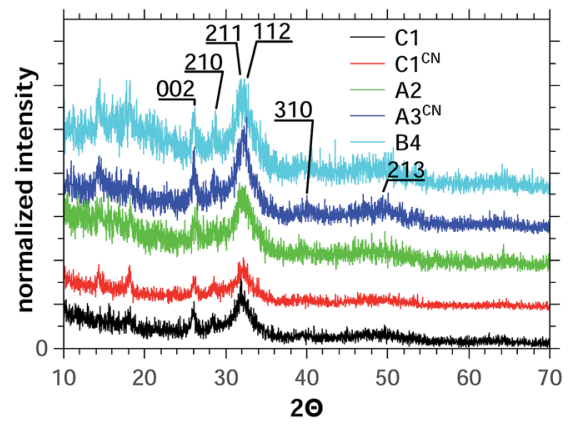

Fig. 6 (A) Ca/P ratios obtained from EDX data of precipitates and (B) XRD patterns of precipitates. ${ }^{86}$ The dashed lines in (A) represent the Ca/P ratios of the different calcium phosphate phase ${ }^{28} \mathrm{OCP}$ is octacalcium phosphate, ACP is amorphous calcium phosphate, HAP is hydroxyapatite, and DCPA is dicalcium phosphate anhydrate (monetite). 

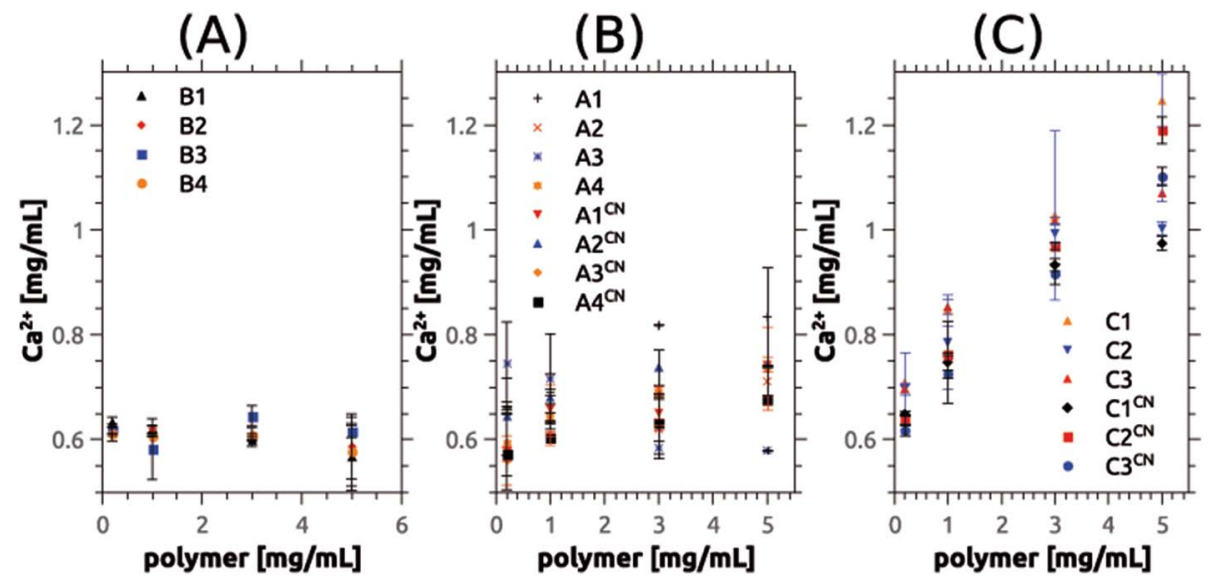

Fig. 7 Absolute data of dissolution experiments showing concentration of calcium removed from the synthetic HAP powder vs. polymer chemistry and concentration. Panels show data from (A) betainic, (B) ampholytic, and (C) cationic copolymers.

A)

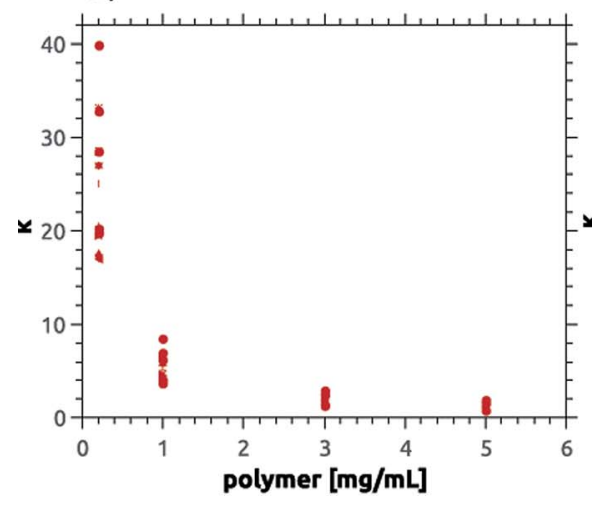

B)

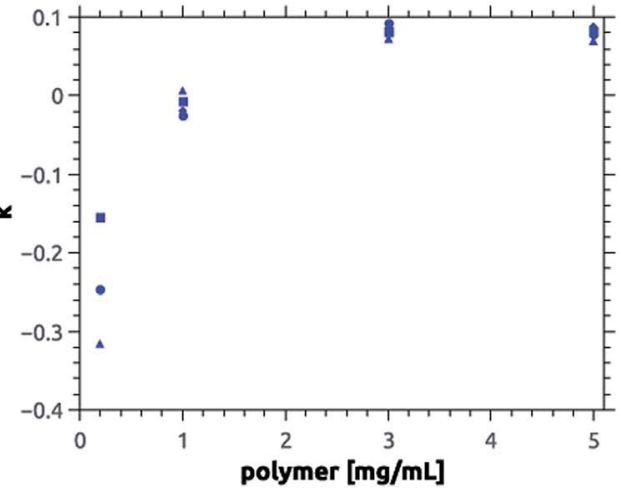

Fig. 8 Calcium dissolution per virtual monomer unit, $\kappa$. Panel (A) shows values for cationic, ampholytic and betainic polymers and (B) for anionic polymers. ${ }^{65,88}$ Note the differences in the $y$-axis between (A) and (B).

dissolution efficiency $v s$. numbers of functional monomers instead of polymer concentration and hence allows for the determination of relative dissolution effectiveness. ${ }^{65}$

$$
\kappa=\frac{\left(n_{\text {sample }}\left(\mathrm{Ca}^{2+}\right)-n_{\text {blank }}\left(\mathrm{Ca}^{2+}\right)\right)}{n(\text { monomer })}
$$

However, as $M_{\mathrm{n}}$ and $P$ are obtained from ${ }^{1} \mathrm{H}$ NMR measurements it is not possible to use eqn (1) for the polymers $\mathrm{C} 1, \mathrm{C} 1^{\mathrm{CN}}$, $\mathrm{A} 1, \mathrm{~A} 1^{\mathrm{CN}}$ and $\mathrm{B} 1$ because for these polymers, no signal of the PEO blocks could be obtained. Conversion of eqn (1) to eqn (2), where $M_{\mathrm{n}}$ (polymer) $/ P$ (polymer, ionic block) is the molar mass of a virtual monomer derived from the contribution of both the charged and the uncharged monomers. As the charged blocks are much larger than the PEO blocks, the contribution to this virtual molar mass is essentially caused by the molar mass of the charged monomers. The use of this virtual monomer molar mass enables the calculation of $\kappa$ without knowledge of $M_{\mathrm{n}}$ or $P$. In the case of the charged homopolymers, the virtual molar mass of the monomers calculated in eqn (2) is equal to the real molar mass of the respective monomers.

$$
\kappa=\frac{\left(\gamma_{\text {sample }}\left(\mathrm{Ca}^{2+}\right)-\gamma_{\text {blank }}\left(\mathrm{Ca}^{2+}\right)\right) M_{\mathrm{n}}(\text { polymer })}{M(\mathrm{Ca}) P(\text { polymer }, \text { ionic block }) \gamma(\text { polymer })}
$$

S14 and S15 $\dagger$ and Fig. 8 summarize the change of $\kappa v s$. polymer concentration. Fig. 8 shows that $\kappa$ is large for low polymer concentrations but decreases with increasing concentration of poly(cation)s, poly(ampholyte)s, and poly(betaine)s and reaches a value of 0.1 at a polymer concentration of $3 \mathrm{mg}$ $\mathrm{mL}^{-1}$ and higher. In contrast, the poly(sulfonate)s studied earlier ${ }^{65}$ have slightly negative $\kappa$ values at low polymer concentrations but also reach a value of $c a .0 .1$ at $\mathrm{mg} \mathrm{mL}^{-1}$ and higher.

\section{Discussion}

Polymers are important additives for bioinspired mineralization and demineralization processes of calcium phosphate. The main focus has so far been on negatively charged (co)polymers and the amount of data on the effects of positively charged polymers is much lower. ${ }^{27,28}$ Data on the effects of zwitterionic, ampholytic, or betainic polymers are virtually non-existent. In 
the current article we describe the synthesis of a set of watersoluble cationic, ampholytic and betainic polymers and their role in calcium phosphate mineralization and dissolution. The effects of ampholytic and betainic polymers are described here for the first time.

Polymerization was achieved via controlled radical polymerization. In all cases polymers were obtained, but the yields differ between $c a$. 9 and 90\%. The presence of only positively charged monomers (TMAEMA or CPDMAEMA) dramatically reduces the polymerization efficiency. We currently speculate that the concentration of chloride ions (the counterions in the TMAEMA and CPDMAEMA monomers) in these systems is high enough to partly deactivate the polymerization catalyst, ${ }^{\mathbf{9 1}, \mathbf{9 2}}$ but this hypothesis will need to be investigated in the future. Moreover, the low activity of the high molecular weight initiator MI5 with these two monomers may also be due to the fact that the few available starting groups could not be effectively initiated by the inhibited catalyst.

In contrast, the presence of monomers carrying a negative charge (sulfonate or betaine monomers) dramatically improves the reactivity and higher yields were obtained. This is possibly due to the fact that less chloride is present in these systems leading to less deactivation of the polymerization catalyst.

Polymer characterization has turned out to be a challenge, mostly due to the somewhat limited solubility of the polymers with mixed charges. Although a number of experimental methods has been used for characterization (GPC, AF4, ${ }^{1} \mathrm{H}$ NMR, Table 1) only ${ }^{1} \mathrm{H}$ NMR provided information on a large fraction of the polymers. NMR spectroscopy confirms that in all cases polymers with very high molecular weights are obtained. GPC only provided reliable results for the positively charged samples, similar to other reports..$^{85,93}$ The other polymers could not be investigated due to strong column-sample interactions.

Polymer analysis using AF4 was only possible for eight polymers (Table 1). The other polymers led to a strong membrane contamination due to strong interactions of the polymers with the membrane used in these experiments. Static light scattering (SLS) provided inconclusive results; this is mainly due to low $\mathrm{d} n / \mathrm{d} c$ values and to the presence of at least two different species in the scattering data, indicating at least partial aggregation of the polymers. This is not unexpected because even polymers containing only hydrophilic blocks such as those studied here have been shown to aggregate in aqueous solution. ${ }^{94-98}$

One of the main goals of this study is the evaluation of the polymers as additives for calcium phosphate dissolution and precipitation. Precipitation experiments were done via an established method ${ }^{65}$ and revealed a consistent delay of the precipitation with polymer addition when compared to polymer-free control reactions. The differences between the different polymers are small. Moreover and somewhat surprisingly the efficiency of the polymers in delaying calcium phosphate precipitation is comparable to the anionic polymers studied earlier ${ }^{65}$ (Fig. 4). These data suggest that the type of charge is not the key effect here. Rather the high molecular weight and the accordingly high number of (positively and/or negatively) charged groups in the polymers may be sufficient to effectively trap very small aggregates, clusters or tiny nanoparticles. Likely, this is achieved by a combination of classical colloidal forces such as electrostatic, steric and electrosteric stabilization combined with a high affinity of the polyelectrolyte blocks to the first (small) inorganic precipitates. This hypothesis is further supported by the observation that the largest block copolymers delay calcium phosphate precipitation most effectively (Fig. 4) and by the fact that in all cases rounded and highly aggregated particles are observed in the SEM (Fig. 5).

Similar to the particle morphology, the crystal phase of the precipitates is indifferent to the exact chemical composition of the polymers as XRD (Fig. 6) always finds HAP as the product. The formation of HAP is further supported by EDXS (Fig. 6). With one exception, the $\mathrm{Ca} / \mathrm{P}$ ratios determined by EDXS are between 1.33 and 1.53; in combination with XRD this suggests the formation of calcium deficient HAP. The formation of calcium deficient HAP in biomimetic syntheses is common, but it is again interesting to note that the polymer charge appears to be of minor importance in the mineralization reaction. This suggests that, consistent with literature, ${ }^{\mathbf{9 9 , 1 0 0}}$ the $\mathrm{pH}$ during precipitation dominates the selection of the calcium phosphate phase. In contrast the charged groups of the polymers are mostly responsible for polymer-inorganic interaction and for trapping small clusters or particles; this in turn thus mostly affects particle sizes and morphologies rather than the crystal structure.

So far, the data of the current and the previous study ${ }^{65}$ therefore suggest that there is only a general and relatively unspecific effect of the charged polymers, but the type of charge (positive, negative, or mixed) appears less important, at least in the current case. This applies to both the morphology (spherical) and the composition (calcium deficient HAP). The sole exception can be observed when purely negatively charged polymers are used, as here the particles are still spherical and still consist of calcium deficient HAP, but the particles are larger and less aggregated than in all cases described here. ${ }^{65}$

As the surface of HAP is slightly negatively charged, ${ }^{80}$ polymers containing positively charged groups such as those investigated here, could favorably interact with HAP-like clusters or particles via electrostatic interaction. This interaction could lead to a strong growth inhibition and it could also be responsible for the much stronger aggregation of the particles than observed with the purely anionic additives observed before. ${ }^{65}$ Overall, these data show that betaines or ampholytes are interesting polymer additives for controlling and optimizing calcium phosphate mineralization.

Finally, as dental care is a potential field of application of these polymers, we have also investigated the resistance of synthetic HAP (as a simple model for enamel HAP) towards exposure of the polymers (Fig. 7, 8, S14 and S15†). The "enamel" loss here is presented by the calcium concentration in the solution after the experiment. Regardless of whether the calcium is free ionic or bound in clusters or nanoparticles it stems from damage of the enamel.

Consistent with the precipitation reactions described above, the effects of the negatively charged sulfonate copolymers differ from the effects observed here. Cationic, ampholytic, and betainic polymers show the same calcium phosphate 
dissolution capacity per virtual repeating unit, $\kappa$. As shown in Fig. 8, a plot of $\kappa v s$. polymer concentration shows that all polymers containing positively charged moieties exhibit a decreasing dissolution efficiency (i.e. a higher degree of protection or stabilization of the "enamel") with increasing polymer concentration. In contrast, the poly(sulfonate)s show an increased dissolution efficiency $v s$. the polymer concentration $^{65}$ resulting in a stronger destabilization of the "enamel" with increasing polymer concentration. Surprisingly all polymers approach a comparable limit of about $\kappa=0.1$ but for the anionic polymers there is a stabilizing effect for HAP at low polymer concentration while there is a clear destabilizing effect for all polymers of the present study at low concentrations.

We currently speculate that this is again caused by the negatively charged HAP surface, ${ }^{\mathbf{8 0}}$ similar to the delayed precipitation discussed above. Electrostatic interactions between the negatively charged HAP surface and the positively charged groups of the polymer will lead to an enrichment of the polymer at the HAP surface. In the case of ampholytic or betainic polymers, this will also lead to the effective interaction of calcium ions and the sulfonate groups present in the polymer. As a result, these polymers will have an enhanced calciumsulfonate contact, which will result in an enhanced HAP dissolution. For the polymers containing cationic moieties there is an analogous interaction present between the ammonium groups and the phosphate on the surface the HAP. The reduced dissolution efficiency at higher polymer concentrations is likely due to the fact that the HAP surfaces are more densely covered with polymer and the removal of calcium from the HAP is therefore more difficult.

The different effects observed with the negatively charged polymers may be due to a weaker interaction of these polymers with the negatively charged HAP surface due to electrostatic repulsion. As a result, there are less calcium-sulfonate contacts, resulting in a reduced HAP dissolution at low polymer concentrations. Increasing polymer concentration may again lead to a more pronounced interaction of the polymer with the HAP surface and the formation of a polymer layer on the surface. This interpretation is consistent with several other studies ${ }^{56,65-67,101}$ where highly negatively charged polymers have been shown to interact quite differently with calcium phosphate than highly positively charged additives.

\section{Conclusion}

The current study shows that high molecular weight block copolymers with cationic, ampholytic, and betainic blocks can effectively be synthesized by controlled radical polymerization. The polymers have two common properties when compared to one another and to poly(sulfonate) copolymers: (1) all polymers delay the nucleation and growth of calcium phosphate by about the same factor and (2) there is no influence of the polymers on the crystal phase of the precipitates. There are, however, also two significant differences between the purely anionic (co) polymers and all other polymers: (1) only the poly(sulfonate) copolymers yield individual, large micrometer-sized spherical particles, while in all other cases, nanometer-sized and highly aggregated particles are observed and (2) the poly(sulfonate)s show a distinctly different behavior in calcium phosphate dissolution experiments. The reasons for these similarities and differences are likely to be found in electrostatic interactions of the polymers and the surface of HAP or one of its precursors.

\section{Acknowledgements}

We thank Dr M. Heydenreich, A. Krtitschka, Y. Linde, A. Musiol, and A. Städtke for help with NMR spectroscopy, EA, and ICPOES, respectively. The Max Planck Institute of Colloids \& Interfaces and the University of Potsdam are thanked for financial support.

\section{References}

1 J. D. B. Featherstone and A. Lussi, Monogr. Oral Sci., 2006, 20, 66-76.

2 T. D. White, M. T. Black and P. A. Folkens, Human Osteology, Elsevier Science, 2011.

3 C. A. Hemaingway, A. J. White, R. P. Shellis, M. Addy, D. M. Parker and M. E. Barbour, Caries Res., 2010, 44, 525-530.

4 J. O. Grippo, M. Simring and T. a. Coleman, J. Esthet. Restor. Dent., 2012, 24, 10-23.

5 S. Kashket, J. Zhang and J. van Houte, J. Dent. Res., 1996, 75, 1885-1891.

6 A. Lussi, T. Jaeggi and D. Zero, Caries Res., 2004, 38, 34-44 Suppl 1.

7 A. C. Magalhães, A. Wiegand, D. Rios, M. A. R. Buzalaf and A. Lussi, Monogr. Oral Sci., 2011, 22, 158-170.

8 N. Schlueter, J. Klimek and C. Ganss, Clin. Oral Investig., 2011, 15, 361-367.

9 N. Schlueter, M. Hardt, A. Lussi, F. Engelmann, J. Klimek and C. Ganss, Eur. J. Oral Sci., 2009, 117, 427-434.

10 N. Schlueter, L. Neutard, J. von Hinckeldey, J. Klimek and C. Ganss, Acta Odontol. Scand., 2010, 68, 180-184.

11 S. Miller, T. Truong, R. Heu, M. Stranick, D. Bouchard and A. Gaffar, Int. Dent. J., 1994, 44, 83-98.

12 W. Wade, M. Addy, J. Hughes, S. Milsom and F. Doherty, J. Clin. Periodontol., 1997, 24, 81-85.

13 G. S. Ingram, E. A. Agalamanyi and S. M. Higham, J. Dent., 2005, 33, 187-191.

14 A. Kovtun, D. Kozlova, K. Ganesan, C. Biewald, N. Seipold, P. Gaengler, W. H. Arnold and M. Epple, RSC Adv., 2012, 2, 870 .

15 M. A. S. Melo, L. Cheng, M. D. Weir, R.-C. Hsia, L. K. a. Rodrigues and H. H. K. Xu, J. Biomed. Mater. Res., Part B, 2013, 101, 620-629.

16 C. Chen, M. D. Weir, L. Cheng, N. J. Lin, S. Lin-Gibson, L. C. Chow, X. Zhou and H. H. K. Xu, Dent. Mater., 2014, 30, 891-901.

17 M. Sin, Y. Sun and Y. Chang, ACS Appl. Mater. Interfaces, 2014, 6, 861-873.

18 S.-J. Ahn, S.-J. Lee, J.-K. Kook and B.-S. Lim, Dent. Mater., 2009, 25, 206-213. 
19 N. B. Arweiler, T. M. Auschill, N. Donos and A. Sculean, Clin. Oral Investig., 2002, 6, 205-209.

20 S. Twetman, A. Hallgren and L. G. Petersson, Caries Res., 1995, 29, 188-191.

21 P. Tschoppe, D. L. Zandim, P. Martus and A. M. Kielbassa, J. Dent., 2011, 39, 430-437.

22 A. Lussi, Monogr. Oral Sci., 2006, 20, 1-8.

23 E. Combe, F. J. T. Burke and D. W. Bernard, Dental Biomaterials, Springer, US, 2013.

24 A. Shimotoyodome, T. Koudate, H. Kobayashi, J. Nakamura, I. Tokimitsu, T. Hase, T. Inoue, T. Matsukubo and Y. Takaesu, Antimicrob. Agents Chemother., 2007, 51, 36343641.

25 J. D. Rogers, R. J. Palmer, P. E. Kolenbrander and F. A. Scannapieco, Infect. Immun., 2001, 69, 7046-7056.

26 J. Li, E. J. Helmerhorst, C. W. Leone, R. F. Troxler, T. Yaskell, a. D. Haffajee, S. S. Socransky and F. G. Oppenheim, J. Appl. Microbiol., 2004, 97, 1311-1318.

27 K. Bleek and A. Taubert, Acta Biomater., 2013, 9, 6283-6321.

28 S. Schweizer and A. Taubert, Macromol. Biosci., 2007, 7, 1085-1099.

29 S. V. Dorozhkin and M. Epple, Angew. Chem., 2002, 114, 3260-3277.

30 R. Kniep and S. Busch, Angew. Chem., Int. Ed. Engl., 1996, 35, 2624-2626.

31 S. Busch, H. Dolhaine, A. DuChesne, S. Heinz, O. Hochrein, F. Laeri, O. Podebrad, U. Vietze, T. Weiland and R. Kniep, Eur. J. Inorg. Chem., 1999, 1999, 1643-1653.

32 P. Simon, W. Carrillo-Cabrera, P. Formánek, C. Göbel, D. Geiger, R. Ramlau, H. Tlatlik, J. Buder and R. Kniep, J. Mater. Chem., 2004, 14, 2218.

33 R. Kniep and P. Simon, Biomineralization, 2007, 270, 73125.

34 H. Tlatlik, P. Simon, A. Kawska, D. Zahn and R. Kniep, Angew. Chem., Int. Ed. Engl., 2006, 45, 1905-1910.

35 P. Simon, U. Schwarz and R. Kniep, J. Mater. Chem., 2005, 15, 4992.

36 S. Busch, U. Schwarz and R. Kniep, Adv. Funct. Mater., 2003, 13, 189-198.

37 S. B. Huang, S. S. Gao and H. Y. Yu, Biomed. Mater., 2009, 4, 034104.

38 F. D. Babcock, J. C. King and T. H. Jordan, J. Dent. Res., 2015, 57, 933-938.

39 C. Ganss, N. Schlueter, M. Hardt, P. Schattenberg and J. Klimek, Caries Res., 2008, 42, 2-7.

40 M. E. Barbour, R. P. Shellis, D. M. Parker, G. C. Allen and M. Addy, Eur. J. Oral Sci., 2005, 113, 457-461.

41 M. Beyer, J. Reichert, E. Heurich, K. D. Jandt and B. W. Sigusch, Dent. Mater. Off. Publ. Acad. Dent. Mater., 2010, 26, 831-839.

$42 \mathrm{~W}$. A. van der Reijden, M. J. Buijs, J. J. Damen, E. C. Veerman, J. M. ten Cate and A. V. Nieuw Amerongen, Caries Res., 1997, 31, 216-223.

43 E. Zhulina, A. V. Dobrynin and M. Rubinstein, Eur. Phys. J. E, 2001, 5, 41-49.

44 M. Zhang, A. Ishii, N. Nishiyama, S. Matsumoto, T. Ishii, Y. Yamasaki and K. Kataoka, Adv. Mater., 2009, 21, 3520-3525.
45 Y.-Y. Hu, X. P. Liu, X. Ma, A. Rawal, T. Prozorov, M. Akinc, S. K. Mallapragada and K. Schmidt-Rohr, Chem. Mater., 2011, 23, 2481-2490.

46 M. J. Joralemon, S. McRae and T. Emrick, Chem. Commun., 2010, 46, 1377-1393.

47 M. J. Roman, E. a. Decker and J. M. Goddard, ACS Appl. Mater. Interfaces, 2014, 6, 5383-5387.

48 A. Tsortos and G. H. Nancollas, J. Colloid Interface Sci., 2002, 250, 159-167.

49 P. Bar-Yosef Ofir, R. Govrin-Lippman, N. Garti and H. Füredi-Milhofer, Cryst. Growth Des., 2004, 4, 177-183.

50 Y. Xu, A. Walther and A. H. E. Müller, Macromol. Rapid Commun., 2010, 31, 1462-1466.

51 A. V. Dobrynin, R. H. Colby and M. Rubinstein, J. Polym. Sci., Part B: Polym. Phys., 2004, 42, 3513-3538.

52 J. Plank, A. Brandl and N. R. Lummer, J. Appl. Polym. Sci., 2007, 106, 3889-3894.

53 A. Habbaba and J. Plank, J. Am. Ceram. Soc., 2010, 93, 28572863.

54 O. Casse, O. Colombani, K. Kita-Tokarczyk, A. H. E. Müller, W. Meier and A. Taubert, Faraday Discuss., 2008, 139, 179.

55 J. Ye, D. Wang, D. N. Zeiger, W. C. Miles and S. Lin-gibson, Biomacromolecules, 2013, 14, 3417-3422.

56 R. J. Coleman, K. S. Jack, S. Perrier and L. Grøndahl, Cryst. Growth Des., 2013, 13, 4252-4259.

57 T. Iwatsubo, S. P. Kusumocahyo, T. Kanamori and T. Shinbo, J. Appl. Polym. Sci., 2006, 100, 1465-1470.

58 T. Iwatsubo, K. Sumaru, T. Kanamori, T. Shinbo and T. Yamaguchi, Biomacromolecules, 2006, 7, 95-100.

59 L.-J. Zhang, H.-G. Liu, X.-S. Feng, R.-J. Zhang, L. Zhang, Y.-D. Mu, J.-C. Hao, D.-J. Qian and Y.-F. Lou, Langmuir, 2004, 20, 2243-2249.

60 M. Kanapathipillai, Y. Yusufoglu, A. Rawal, Y.-Y. Hu, C.-T. Lo, P. Thiyagarajan, Y. E. Kalay, M. Akinc, S. Mallapragada and K. Schmidt-Rohr, Chem. Mater., 2008, 20, 5922-5932.

61 Y. Yusufoglu, Y. Hu, M. Kanapathipillai, M. Kramer, Y. E. Kalay, P. Thiyagarajan, M. Akinc, K. Schmidt-Rohr and S. Mallapragada, J. Mater. Res., 2011, 23, 3196-3212.

62 L. Chen, K. Liang, J. Li, D. Wu, X. Zhou and J. Li, Arch. Oral Biol., 2013, 58, 975-980.

63 P. Schaad, J.-M. Thomann, J.-C. Voegel and P. Gramain, Colloids Surf., A, 1994, 83, 285-292.

64 P. Schaad, J.-M. Thomann, J.-C. Voegel and P. Gramain, J. Colloid Interface Sci., 1994, 164, 291-295.

65 T. Mai, E. Rakhmatullina, K. Bleek, S. Boye, J. Yuan, A. Völkel, M. Gräwert, Z. Cheaib, S. Eick, C. Günter, A. Lederer, A. Lussi and A. Taubert, Biomacromolecules, 2014, 15, 3901-3914.

66 M. Junginger, K. Kita-Tokarczyk, T. Schuster, J. Reiche, F. Schacher, A. H. E. Müller, H. Cölfen and A. Taubert, Macromol. Biosci., 2010, 10, 1084-1092.

67 M. Junginger, K. Bleek, K. Kita-Tokarczyk, J. Reiche, A. Shkilnyy, F. Schacher, A. H. E. Müller and A. Taubert, Nanoscale, 2010, 2, 2440-2446.

68 A. Shkilnyy, J. Brandt, A. Mantion, O. Paris, H. Schlaad and A. Taubert, Chem. Mater., 2009, 21, 1572-1578. 
69 S. Grohmann, H. Rothe and K. Liefeith, Biointerphases, 2012, 7, 1-13.

70 S. Segman-Magidovich and H. Rapaport, J. Phys. Chem. B, 2012, 116, 11197-11204.

71 P. Liu and J. Song, Biomaterials, 2013, 34, 2442-2454.

72 S. Lin, J. Wu, H. Jia, L. Hao, R. Wang and J. Qi, RSC Adv., 2013, 3, 20758-20764.

73 B. B. Hsu and A. M. Klibanov, Biomacromolecules, 2011, 12, 6-9.

74 D. Park, J. Wang and A. M. Klibanov, Biotechnol. Prog., 2006, 22, 584-589.

75 R. Quintana, M. Gosa, D. Jańczewski, E. Kutnyanszky and G. J. Vancso, Langmuir, 2013, 29, 10859-10867.

76 Y. Chang, W.-J. Chang, Y.-J. Shih, T.-C. Wei and G.-H. Hsiue, ACS Appl. Mater. Interfaces, 2011, 3, 1228-1237.

77 J. B. Schlenoff, Langmuir, 2014, 30, 9625-9636.

78 S. Kudaibergenov, W. Jaeger and A. Laschewsky, in $A d v$. Polym. Sci., 2006, vol. 201, pp. 157-224.

79 S. E. Kudaibergenov, in Polymer Latexes - Epoxide Resins Polyampholytes, Springer Berlin Heidelberg, Berlin, Heidelberg, 1999, pp. 115-197.

80 J. Vandiver, D. Dean, N. Patel, W. Bonfield and C. Ortiz, Biomaterials, 2005, 26, 271-283.

81 Marvin was used for drawing, displaying and characterizing chemical structures, substructures and reactions, Marvin 15.11.16.0, ChemAxon, 2015, http://www.chemaxon.com.

82 E. W. A. F. Holleman, Lehrbuch der anorganischen Chemie, deGruyter, 101. Aufl., 1995.

83 W. L. F. Armarego and C. Chai, Purification of Laboratory Chemicals, Elsevier Science, Sixth edn, 2009.

84 T. Kokubo, S. Ito, Z. T. Huang, T. Hayashi, S. Sakka, T. Kitsugi and T. Yamamuro, J. Biomed. Mater. Res., 1990, 24, 331-343.

85 K. E. S. Locock, L. Meagher and M. Haeussler, Anal. Chem., 2014, 86, 2131-2137.

86 M. Wagner, C. Pietsch, L. Tauhardt, A. Schallon and U. S. Schubert, J. Chromatogr. A, 2014, 1325, 195-203.
87 J. C. Salamone, L. Quach, A. C. Watterson, S. Krauser and M. U. Mahmud, J. Macromol. Sci., Part A: Pure Appl. Chem., 1985, 22, 653-664.

88 I. Vasilef, QTIPLOT, Data Analysis and Scientific Visualisation, Universiteit Utrecht, Utrecht, Niederlande, 2011.

89 E. D. Eanes, in Octacalcium Phosphate, Karger, Basel, 2001, vol. 18, pp. 130-147.

90 W. J. E. M. Habraken, J. Tao, L. J. Brylka, H. Friedrich, L. Bertinetti, A. S. Schenk, A. Verch, V. Dmitrovic, P. H. H. Bomans, P. M. Frederik, J. Laven, P. van der Schoot, B. Aichmayer, G. de With, J. J. deYoreo and N. a. J. M. Sommerdijk, Nat. Commun., 2013, 4, 1507.

91 N. V. Tsarevsky, T. Pintauer and K. Matyjaszewski, Macromolecules, 2004, 37, 9768-9778.

92 W. Tang and K. Matyjaszewski, Macromolecules, 2007, 40, 1858-1863.

93 T. D. Michl, K. E. S. Locock, N. E. Stevens, J. D. Hayball, K. Vasilev, A. Postma, Y. Qu, A. Traven, M. Haeussler, L. Meagher and H. J. Griesser, Polym. Chem., 2014, 5, 5813.

94 A. Blanazs, N. J. Warren, A. L. Lewis, S. P. Armes and A. J. Ryan, Soft Matter, 2011, 7, 6399-6403.

95 O. Casse, A. Shkilnyy, J. Linders, C. Mayer, D. Häussinger, A. Völkel, A. F. Thünemann, R. Dimova, H. Cölfen, W. Meier, H. Schlaad and A. Taubert, Macromolecules, 2012, 45, 4772-4777.

96 W. Agut, A. Brûlet, D. Taton and S. Lecommandoux, Langmuir, 2007, 23, 11526-11533.

97 M. Arotçaréna, B. Heise, S. Ishaya and A. Laschewsky, J. Am. Chem. Soc., 2002, 124, 3787-3793.

98 J. H. Lee and M. L. Shofner, Langmuir, 2013, 29, 1094010944.

99 R. Palanivelu, A. Mary Saral and A. Ruban Kumar, Spectrochim. Acta, Part A, 2014, 131, 37-41.

$100 \mathrm{X} . \mathrm{Lu}$ and Y. Leng, Biomaterials, 2005, 26, 1097-1108.

101 V. Ball, M. Michel, F. Boulmedais, J. Hemmerle, Y. Haikel, P. Schaaf and J. C. Voegel, Cryst. Growth Des., 2006, 6, 327334. 